\title{
Repeat Gamma Knife surgery for recurrent trigeminal neuralgia: long-term outcomes and systematic review
}

\author{
Clinical article
}

\author{
Constantin Tuleasca, M.D., ${ }^{1,4-7}$ Romain Carron, M.D., Ph.D., ${ }^{1}$ \\ NoÉmie Resseguier, M.D., M.Sc., ${ }^{2}$ AnNe Donnet, M.D., ${ }^{3}$ Philippe Roussel, M.D. ${ }^{1}{ }^{1}$ \\ Jean Gaudart, M.D., Ph.D., ${ }^{2}$ Marc Levivier, M.D., Ph.D., ${ }^{6,7}$ and Jean Régis, M.D. ${ }^{1}$ \\ ${ }^{1}$ INSERM U 751 (Université de la Méditerranée), Functional and Stereotactic Neurosurgery Unit; \\ ${ }^{2}$ Department of Public Health and Medical Information and UMR 912 (INSERM-IRD-Université de la \\ Méditerranée); and ${ }^{3}$ Department of Neurology, Clinical Neuroscience Federation, Centre Hospitalier \\ Universitaire La Timone Assistance Publique-Hôpitaux de Marseille, France; ${ }^{4}$ Signal Processing \\ Laboratory (LTS 5), École polytechnique fédérale de Lausanne; ${ }^{5}$ Medical Image Analysis Laboratory; \\ ${ }^{6}$ Department of Clinical Neurosciences, Neurosurgery Service and Gamma Knife Center, Centre Hospitalier \\ Universitaire Vaudois; and ${ }^{7}$ Faculty of Biology and Medicine, University of Lausanne, Switzerland
}

\begin{abstract}
Object. The purpose of this study was to establish the safety and efficacy of repeat Gamma Knife surgery (GKS) for recurrent trigeminal neuralgia $(\mathrm{TN})$.

Methods. Using the prospective database of TN patients treated with GKS in Timone University Hospital (Marseille, France), data were analyzed for 737 patients undergoing GKS for TN Type 1 from July 1992 to November 2010. Among the 497 patients with initial pain cessation, $34.4 \%$ (157/456 with $\geq 1$-year follow-up) experienced at least 1 recurrence. Thirteen patients $(1.8 \%)$ were considered for a second GKS, proposed only if the patients had good and prolonged initial pain cessation after the first GKS, with no other treatment alternative at the moment of recurrence. As for the first GKS, a single 4-mm isocenter was positioned in the cisternal portion of the trigeminal nerve at a median distance of $7.6 \mathrm{~mm}$ (range 4-14 $\mathrm{mm}$ ) anterior to the emergence of the nerve (retrogasserian target). A median maximum dose of 90 Gy (range 70-90 Gy) was delivered. Data for 9 patients with at least 1-year followup were analyzed. A systematic review of literature was also performed, and results are compared with those of the Marseille study.

Results. The median time to retreatment in the Marseille study was 72 months (range 12-125 months) and in the literature it was 17 months (range 3-146 months). In the Marseille study, the median follow-up period was 33.9 months (range 12-96 months), and 8 of 9 patients (88.9\%) had initial pain cessation with a median of 6.5 days (range 1-180 days). The actuarial rate for new hypesthesia was $33.3 \%$ at 6 months and $50 \%$ at 1 year, which remained stable for 7 years. The actuarial probabilities of maintaining pain relief without medication at 6 months and 1 year were $100 \%$ and $75 \%$, respectively, and remained stable for 7 years. The systematic review analyzed 20 peer-reviewed studies reporting outcomes for repeat GKS for recurrent TN, with a total of 626 patients. Both the selection of the cases for retreatment and the way of reporting outcomes vary widely among studies, with a median rate for initial pain cessation of $88 \%$ (range $60 \%-100 \%$ ) and for new hypesthesia of 33\% (range 11\%-80\%).

Conclusions. Results from the Marseille study raise the question of surgical alternatives after failed GKS for TN. The rates of initial pain cessation and recurrence seem comparable to, or even better than, those of the first GKS, according to different studies, but toxicity is much higher, both in the Marseille study and in the published data. Neither the Marseille study data nor literature data answer the 3 cardinal questions regarding repeat radiosurgery in recurrent $\mathrm{TN}$ : which patients to retreat, which target is optimal, and which dose to use.
\end{abstract} (http://thejns.org/doi/abs/10.3171/2014.8.GKS141487)

\section{KeY Words - Gamma Knife surgery stereotactic radiosurgery}

AMMA Knife surgery (GKS) is a noninvasive procedure, increasingly used in many intracranial conditions, including trigeminal neuralgia (TN).

\footnotetext{
Abbreviations used in this paper: $\mathrm{BNI}=$ Barrow Neurological Institute; DREZ = dorsal root entry zone; GKS = Gamma Knife surgery; $\mathrm{MVD}=$ microvascular decompression; $\mathrm{TN}=$ trigeminal neuralgia.
}

Leksell, the inventor of GKS, performed the first radiosurgical treatment in 1951..$^{35,36}$ In 1981, Håkanson discovered that the glycerol injection, made for GKS targeting purposes, could also be used as a therapy in TN. ${ }^{20,21} \mathrm{In}$ 1985 , once MR imaging was available for clinical use on a large scale, modern dose planning was implemented. ${ }^{37}$ In 1993, Rand et al..$^{45,46}$ advocated that the ganglion was not a good target and proposed to shift the target to the 
cisternal part. ${ }^{50}$ In 1996, Kondziolka et al..$^{34}$ published a multicenter study that established the minimal therapeutic dose necessary to be effective. ${ }^{50}$ In 1994 , Lindquist coined the term "dorsal root entry zone (DREZ) target" (corresponding in fact to the anatomical emergence of the trigeminal nerve) ${ }^{37}$ In 2000, Pollock et al ${ }^{43}$ published the first paper on repeat radiosurgery for TN, and in 2006 Régis et al. ${ }^{49}$ published the only prospective controlled trial using GKS as a therapy for medically unresponsive TN.

Since 1996, the number of available papers advocating the safety and efficacy of GKS in idiopathic TN has grown continuously; however, studies describing repeat radiosurgery are scarce. Furthermore, there are no clear-cut guidelines for indication or technique for repeat radiosurgery, such as patient selection criteria for retreatment, dose, location of the isocenter, or whether to plug the collimator apertures. Therefore, we present our own study of patients treated in Timone University Hospital, Marseille, France, and compare our results with systematically reviewed published data on repeat radiosurgery for recurrent TN.

\section{Methods}

\section{Marseille Study}

This was designed as an open, self-controlled, noncomparative, retrospective study. For all patients, a case report form was created and filled in prospectively. All patients were examined before treatment, and MR imaging was performed (the latest images were used to exclude any secondary cases). Permission was obtained from the Timone University Hospital ethics committee for this study.

Patients. Between July 1992 and November 2010, patients presenting with intractable $\mathrm{TN}$ were prospectively selected and treated with radiosurgery in Timone University Hospital, Marseille, France. We included in our study patients undergoing repeat GKS for recurrent TN with more than 1 year of follow-up.

Cases of TN secondary to multiple sclerosis ${ }^{58}$ or due to megadolichobasilar artery compression ${ }^{60}$ were excluded from our analysis, as they are reputed to have different clinical outcomes. (J.R.).

All patients were treated by the senior neurosurgeon

Diagnostic Criteria Using the International Headache Society Definition. All patients fulfilled the TN criteria of the International Headache Society. ${ }^{23}$ Evaluation of the type of trigeminal pain was made according to the classification proposed by Eller et al. ${ }^{15}$ : idiopathic TN Type 1, described as typically sharp, shooting, electrical shock-like, with pain-free intervals between the attacks, present for more than $50 \%$ of the time; and TN Type 2, described as an aching, throbbing, or burning pain, present for more than $50 \%$ of the time and constant in nature (constant background pain being the most significant attribute). Only patients fulfilling the criteria of the TN Type 1 were included in the present study.

Patient Selection Criteria for Retreatment and Technique. Retreatment was proposed only if patients had good and prolonged pain cessation after initial GKS, with no other surgical alternative at the moment of recurrence. We used the same target and same ranges of doses as for the first GKS. All patients underwent repeat GKS. After application of the Leksell Model G stereotactic frame (Elekta $\mathrm{AB}$ ) under local anesthesia, patients underwent stereotactic MR imaging and CT imaging for target definition. The MR image sequences used to identify the trigeminal nerve were T2-type CISS (constructive interference in steady state) (Siemens S.A.S.) without contrast, and contrast-enhanced T1-weighted images. Bone CT imaging routinely supplements the neuroradiological investigation to correct any distortion errors on the MR image. ${ }^{49,59}$

Between July 1992 and November 2010, the Gamma Knife (model B, C, or 4C; Elekta AB) was successively used. A single 4-mm isocenter was used in all patients, for both the first and the second GKS, positioned in the anterior cisternal portion of the trigeminal nerve at a median distance of $7.6 \mathrm{~mm}$ (range 4-14 $\mathrm{mm}$ ) anterior to the emergence of the nerve (retrogasserian target). This target has been used in our center since the beginning of GKS treatments for $\mathrm{TN}$, as detailed in previous studies ${ }^{47-50}$ (Fig. 1).

The median maximum dose delivered during the first treatment was 85 Gy (range 70-90 Gy) and at retreatment it was 90 Gy (range 70-90 Gy). The dose was chosen according to the multicenter trial of Kondziolka et al. ${ }^{34}$ (which included an substantial number of patients from our center), which recommended a minimal dose of 70 Gy for short- and/or long-term efficacy, a cutoff our group was using before the publication of that trial. Furthermore, we initially give a dose of 90 Gy at the $100 \%$ isodose. Beam channel blocking is used based on the dose received by $10 \mathrm{~mm}^{3}$ of the brainstem: if this dose is greater than $15 \mathrm{~Gy}$, we diminish the dose and then start plugging the collimator apertures to avoid increasing the length of the treated nerve, which could account for more toxicity (the so-called Flickinger effect). ${ }^{16}$

Follow-Up Monitoring. Patients and referring physicians were instructed to follow the pretreatment medication regimen for at least 1 month after GKS and then to diminish the doses progressively in periods of pain freedom.

Initial follow-up was based on clinical evaluation at regular intervals of 3 months, 6 months, and 1 year after the treatment and on a yearly basis thereafter. We have personally examined all patients for proper evaluation of safety and efficacy, including facial sensory testing, corneal reflex, and jaw motility. For long-term follow-up, telephone interview was considered acceptable for patients unable to visit the clinic because of either distance or general health-related conditions.

Every clinical evaluation made by our medical team during follow-up was prospectively noted in the database. The 15 items of data considered essential by Zakrzewska and Thomas ${ }^{66}$ for articles reporting outcomes of surgical treatment of $\mathrm{TN}$ were followed.

Explicit Definitions of Outcome Measures. Outcome measures included initial pain cessation and onset and recurrence of the sensory disturbance. Efficacy was classi- 


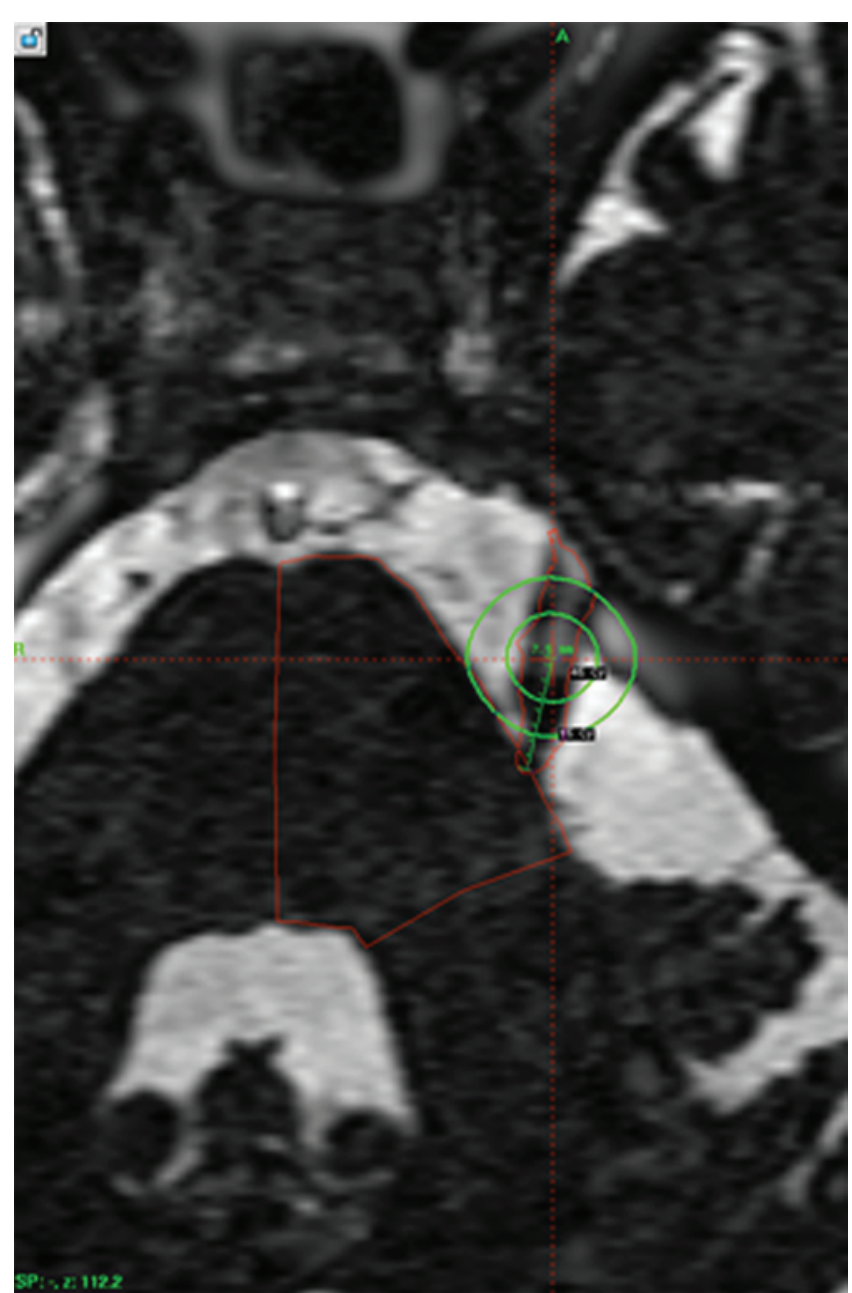

Fig. 1. The retrogasserian target used in our institution (Timone University Hospital, Marseille, France).

fied according to the Barrow Neurological Institute (BNI) scale: Class I, no trigeminal pain, no medication; Class II, occasional pain, not requiring medication; Class IIIa, no pain with continued medication; Class IIIb, pain controlled with medication; Class IV, some pain, not adequately controlled with medication; and Class V, severe pain, no pain relief. A successfully treated patient was considered a patient who was pain free without medication (BNI Class I).

The degree of hypesthesia is reported using the BNI facial hypesthesia scale: Class I, no facial numbness; Class II, mild facial numbness, not bothersome; Class III, facial numbness, somewhat bothersome; and Class IV, facial numbness, very bothersome. ${ }^{51}$ The corneal reflex was assessed for all patients. Additionally, the occurrence or absence of dysesthesias, paresthesias, anesthesia dolorosa, masseter weakness, neurological complications outside the trigeminal nerve territory, systemic complications, and death were noted.

Recurrence was defined as change from Class I to a lower outcome class during follow-up. Thus, recurrence was considered to have happened in a patient who had been pain free without medication (Class I) and who then started taking specific drugs again but who remained pain free on medication (Class II).
A minor recurrence was defined as one that was well tolerated by the patient (lower frequency and intensity of the pain) and did not require additional treatment. A major recurrence was defined as one requiring a surgical procedure. We use the term "initial efficacy" when a patient is pain free with or without medication in the first 6 months after the radiosurgery and has no recurrence in the year that follows the procedure.

The latency intervals to becoming pain free or developing a recurrence or a sensory disturbance, the date of medication changes, and the date of all surgical procedures were also monitored. Patient satisfaction was evaluated at the last follow-up.

Statistical Analysis. All statistical analyses were performed using $\mathrm{R}$ software (version 2.12.0, R Foundation for Statistical Computing). The R package "survival" was used for survival analysis. For the evaluation of outcomes such as pain free, hypesthesia, and recurrence, time to event was estimated using the Kaplan-Meier method. A bivariate analysis was then performed to identify predictive factors among the collected variables. Qualitative variables were compared using the univariate log-rank test, with survival among the different groups represented graphically with Kaplan-Meier curves. For all variables, the effects were estimated and tested by fitting univariate Cox proportional hazards regression models. Proportionality of hazards was assessed graphically by log cumulative hazard plots. For qualitative variables, chi-square tests were performed when valid; otherwise, exact Fisher tests were used. For quantitative variables, Mann-Whitney tests were performed given the number of patients. All tests were 2 -sided, and p values $<0.05$ were deemed significant.

\section{Systematic Review}

Search Strategy and Selection Criteria. The PubMed database was queried using the following word combinations in the "title" item: "repeat" AND "radiosurgery" AND "trigeminal"), ("recurrent" AND "radiosurgery" AND "trigeminal"), and ("salvage" AND "radiosurgery" AND "trigeminal"). The bibliographies of the identified studies were also searched to ensure that no qualifying references were missed. Additionally, we used the Google search engine to expand our list of studies, including abstracts, but we considered in the final analysis only peerreviewed papers. We did not restrict returns by year of publication; all published studies were eligible for selection if they fulfilled the criteria. There were no language restrictions.

Suitable studies were peer reviewed and contained data on patients who underwent repeat radiosurgery for recurrent $\mathrm{TN}$, and reported rates of initial pain cessation, hypesthesia, and recurrence. Papers reporting retreatment as a subgroup were included if they had a minimum number of 13 cases, as this was the number of our study. We excluded studies that did not meet these criteria.

Three investigators (C.T., M.L., and J.R.) extracted data independently and in duplicate and assessed trial eligibility and quality. Disagreements were resolved by consensus. 
Outcomes. We extracted the primary outcomes, initial pain cessation, hypesthesia, and recurrence, and their positive and negative predictive factors. Secondary data extracted were selection criteria and patient profile for retreatment, the number of retreatments versus the total number of patients in the same institution/trial, mean/ median interval between first and second radiosurgical treatments, placement of the target and the doses used for first and second treatments, complications other than hypesthesia, and criteria used to report the outcomes.

\section{Results}

\section{Marseille Study}

Between July 1992 and November 2010, 737 patients were treated for TN at Timone University Hospital (Marseille, France). Among the 497 patients in our study with initial pain cessation after the first GKS, 34.4\% (157 of 456 patients with $\geq 1$-year follow-up) experienced at least 1 recurrence. Thirteen of the 737 patients $(1.8 \%)$ had repeat GKS for recurrent TN; 9 patients with more than 1 year of follow-up were further analyzed. The median follow-up period for these 9 patients was 33.9 months (range 12-96 months). The median age at second GKS was 64.4 years (range 53.7-83.1 years). All the patients presented with typical TN Type 1 pain.

Details of Previous Treatments. Previous treatments are detailed in Table 1 . All patients $(100 \%)$ had prior surgical procedures, of whom 4 (44.4\%) had only 1 previous intervention, $2(22.2 \%)$ had 2 previous surgeries, and 3 (33.4\%) had 3 or more previous surgeries. Previous surgeries consisted of radiofrequency lesioning in 4 patients (44.4\%), balloon microcompression in 1 (11.1\%), and microvascular decompression (MVD) in $1(11.1 \%)$. Before GKS, 3 patients $(33.3 \%)$ had sensory disturbance related to a previous surgical procedure, consisting of slight hypesthesia in $2(22.2 \%)$ and severe hypesthesia in 1 (11.1\%).

Initial Rate of Pain Cessation. Eight of 9 patients (88.9\%) were initially pain free in a median time of 6.5 days (range 1-180 days) after retreatment and 10 days (range 1-180 days) after first GKS. The initially pain cessation actuarial rate at $0.5,1,2,3,4,5$, and 6 months was, respectively, $53.52 \%, 73 \%, 83.5 \%, 88.1 \%, 88.9 \%, 89.5 \%$, and $91.3 \%$ after the first GKS (Fig. 2) and 33.3\%, 44.4\%, $44.4 \%, 55.6 \%, 55.6 \%, 66.7 \%$, and $88.9 \%$ after retreatment. No statistically significant predictors were found for being initially pain free after the second GKS, but the small number of patients limits statistical power.

Postoperative Sensory Assessment. No patients sustained early complication after the second GKS. Three patients (33.3\%) developed later objective facial sensory loss, which occurred during the 1st year after retreatment and was mild in all cases. The hypesthesia actuarial rate was $33.3 \%$ at 6 months; at 1 year it reached $50 \%$ and remained stable for 7 years (Fig. 3). For all patients with idiopathic TN treated in our institution, we have reported a hypesthesia actuarial rate of $21 \%$ after first GKS; ${ }^{48}$ in our study of patients undergoing repeat radiosurgery,
TABLE 1: Pretreatment assessment in the Marseille study $(n=9)$

\begin{tabular}{ll}
\hline \multicolumn{1}{c}{ Variable } & No. of Patients $(\%)$ \\
\hline side of pain & $6(66.7)$ \\
right & $3(33.3)$ \\
left & $9(100)$ \\
no. of prior treatments & $4(44.4)$ \\
1 & $2(22.2)$ \\
2 & $3(33.4)$ \\
$\geq 3$ & \\
type of prior treatment & $9(100)$ \\
GKS & $4(44.4)$ \\
radiofrequency lesioning & $1(11.1)$ \\
balloon microcompression & $1(11.1)$ \\
MVD & $3(33.3)$ \\
side effects from prior surgery & \\
facial sensation before GKS & $6(60.5)$ \\
normal & $2(22.2)$ \\
slight hypesthesia & $1(11.1)$ \\
severe hypesthesia &
\end{tabular}

we found a statistically significant higher risk of facial numbness ( $\mathrm{p}=0.0193$; hazard ratio 3.97). We also assessed hypesthesia according to the BNI facial hypesthesia scale; mild facial numbness occurred in all 3 patients. No patient developed a trigeminal motor deficit or other cranial nerve deficit, or anesthesia dolorosa or dry eye syndrome after GKS. When asked about their quality of life, all patients considered the presence of hypesthesia to be a good tradeoff for the disappearance of pain. No statistically significant predictors were found for complications after the second GKS, but the small number of patients limits statistical power.

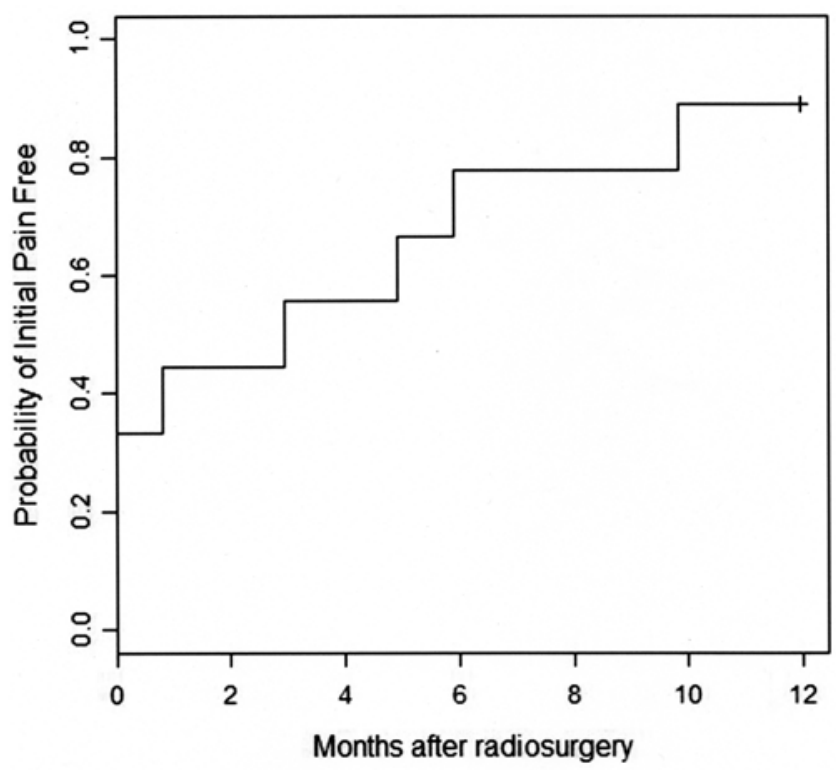

FIG. 2. Kaplan-Meier curve showing the actuarial pain cessation rates in our series after second GKS (9 patients with $\geq 1$-year follow-up). 


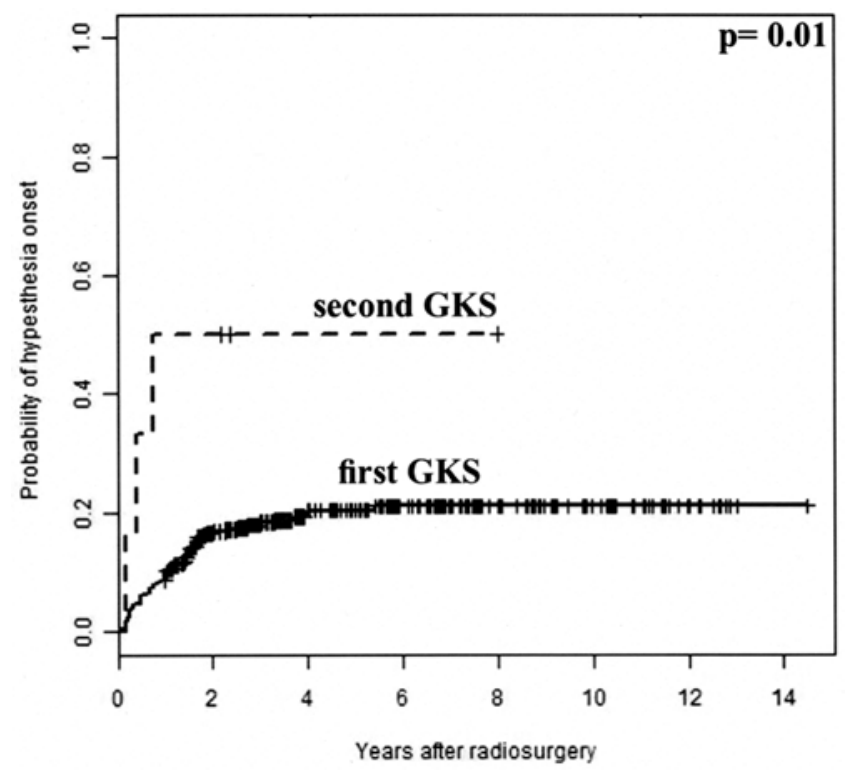

FIG. 3. Kaplan-Meier curve showing the actuarial hypesthesia rates for first GKS (solid line) and second GKS (dashed line).

Management and Results of Recurrent Pain. Two patients $(22.2 \%)$ who were initially pain free after GKS experienced a recurrence. The actuarial probability of maintaining pain relief without medication at 6 months was $100 \%$ and at 1 year reached $75 \%$ and remained stable for 7 years (Fig. 4). Patients with pain on the left side (p $=0.04)$ and in the V2 dermatome $(p=0.04)$ had a higher risk of recurrence. No other statistically significant predictors were found, but the small number of patients limits statistical power.

Two patients $(22.2 \%)$ needed an additional treatment after GKS, with 1 surgery in 1 case (11.1\%) and 3 or more surgeries in 1 case (11.1\%). The further surgical procedures

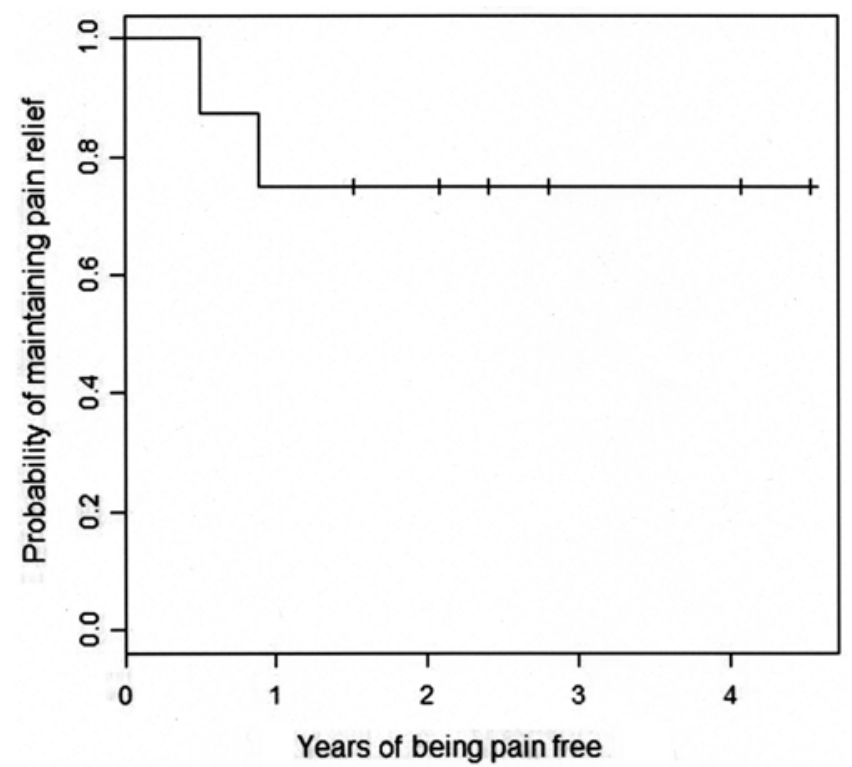

FIg. 4. Kaplan-Meier curve showing the actuarial rate for maintaining pain-relief rates after second GKS in the Marseille study. performed were balloon microcompression in 2 cases (22.2\%) and MVD in 1 case (11.1\%) (Table 2). All patients $(100 \%)$ expressed a high level of satisfaction, did not regret undergoing GKS, and would undergo GKS again.

\section{Systematic Review}

Reports Included. The combination of words "repeat AND radiosurgery AND trigeminal" in PubMed database gave a number of 25 papers, from which 10 were selected, , 514,17,22,24,29,32,40,42,67 including 1 case report; ${ }^{29}$ using "recurrent AND radiosurgery AND trigeminal" returned 48 studies, from which 7 were selected; ;,25-27,43,54,63 and using "salvage" AND "radiosurgery" AND "trigeminal" returned 1 study $^{38}$ that did not report the outcomes of interest, only the range of doses used at retreatment, so we excluded it. After a detailed research of references in the included studies and after analyzing all trials published on idiopathic TN treated with GKS, 3 further studies were included, giving a total of 20 studies (Tables 3-5).

Interestingly, no dedicated study was found when searching for retreatment using linear accelerators, only sparse information without outcomes. ${ }^{13,57}$

Study Analysis. The final analysis included 20 peerreviewed papers treating the subject of repeat GKS for $\mathrm{TN}$, for a total of 626 patients. Only 4 studies contained more than 40 patients. All reports were retrospective and only 4 had long-term follow-up. . $^{17,32,40,62}$ Although this is a large number of patients, analysis was difficult because of study heterogeneity. First, the populations of patients were heterogeneous at baseline, in terms of previous surgeries (highly variable numbers and types) and inclusion of atypical cases and multiple sclerosis, ${ }^{1,32,63}$ which are reputed to have a different initial pain cessation outcomes. ${ }^{58}$ Second, there was no uniformity of patient selection criteria for retreatment. Third, outcomes were assessed differently; quality of life issues were reported sporadically ${ }^{24}$ and, if so, on

TABLE 2: Assessment after second GKS in the Marseille study

\begin{tabular}{ll}
\hline \multicolumn{1}{c}{ Variable } & No. of Patients (\%) \\
\hline initially pain free & $8(88.9)$ \\
post-GKS sensory dysfunction & $3(33.3)$ \\
$\quad$ mild & $3(33.3)$ \\
severe & $0(0)$ \\
BNI facial hypesthesia scale (GKS related) & \\
I (no facial numbness) & $6(66.7)$ \\
II (mild facial numbness) & $3(33.3)$ \\
III (facial numbness, somewhat bothersome) & $0(0)$ \\
IV (facial numbness, very bothersome) & $0(0)$ \\
recurrence of pain & $2(22.2)$ \\
no. of additional treatments after 2nd GKS & $2(22.2)$ \\
1 & $1(11.1)$ \\
2 & $0(0)$ \\
$\geq 3$ & $1(11.1)$ \\
balloon microcompression & $2(22.2)$ \\
MVD & $1(11.1)$ \\
\hline
\end{tabular}


TABLE 3: Systematic review of the literature: demographics of patients undergoing second GKS*

\begin{tabular}{|c|c|c|c|c|c|}
\hline Authors \& Year & $\begin{array}{l}\text { No./Total } \\
\text { Patients }\end{array}$ & Center & $\begin{array}{c}\text { Follow-Up Period in Mos } \\
\text { (range) }\end{array}$ & Age in Yrs (range) & $\begin{array}{l}\text { Mean Interval Btwn } \\
\text { 1st \& 2nd GKS (mos) }\end{array}$ \\
\hline present study & $13 / 737$ & Marseille (France) & median 33.9 (15.9-96) & median 64.4 (53.7-83.1) & median 72 (12-125) \\
\hline Aubuchon et al., 2011 & 37 & Florida (US) & mean 45.6 (7.2-86.4) & NA & mean 15.6 \\
\hline Jones et al., 2011 & 1 & Seattle, WA (US) & 24 & 72 & 11 \\
\hline Kimball et al., 2010 & $45 / 379$ & Memphis, TN (US) & mean $42(1-122)$ & mean $68(30-87)$ & mean $33(3-138)$ \\
\hline Dvorak et al., 2009 & 28 & Boston, MA (US) & median 19.7 (1.7-48.9) & median 63 & median $18.1(9-55.4)$ \\
\hline Gellner et al., 2008 & $22 / 93$ & Graz (Austria) & mean $64.5(13-142)$ & mean 73.5 & mean 18.8 (6-63) \\
\hline Huang et al., 2008 & $20 / 89$ & Taiwan (China) & mean 60 (32-87) & mean $61.8(34-83)$ & mean 8 (4.67) \\
\hline Wang et al., 2008 & $34 / 322$ & X'ian (China) & mean $21.6(7-41)$ & median 68 (42-87) at 1 st GKS & mean $17.4(8-34)$ \\
\hline Huang et al., 2006 & $28 / 118$ & Taiwan (China) & median 43 & median 63 (34-77) & median 8 (3-67) \\
\hline Zhang et al., 2005 & 40 & New York (US) & mean $28(6-51)$ & median 73 (40-90) & mean $17(5-48)$ \\
\hline Herman et al., 2004 & $18 / 112$ & Baltimore, MD (US) & median $24.5(6-65)$ & median 62 (31-89) & median 8 (3-42) \\
\hline Brisman, 2003 & $45 / 335$ & Columbia, SC (US) & mean 15 & mean 70 & mean 18 (42-68) \\
\hline Hasegawa et al., 2002 & $27 / 387$ & Pittsburgh, PA (US) & median 20.4 & mean 68.7 & mean $22.3(6-73)$ \\
\hline Shetter et al., 2002 & $19 / 240$ & Phoenix, AZ (US) & median 13.5 & NA & NA \\
\hline Zheng et al., 2001 & $12 / 80$ & Tianjin (China) & mean 18 & mean 67 (32-92) & NA \\
\hline Pollock et al., 2000 & $10 / 100$ & Rochester, MN (US) & median 15 & median 68 (48-83) & median 13 (4-27) \\
\hline
\end{tabular}

* NA = not applicable.

† The original study published in 2010 by Kondziolka et al. had 503 patients. The paper on retreatments (Park et al., 2012) does not state how many total patients they treated to that date.

different scales. Last but not least, the techniques employed were also highly variable: target placement and dose prescription play a crucial role in outcomes and should not be neglected in this type of analysis.

Outcomes were highly variable, with a median rate of initial pain cessation of $88 \%$ (range 60\%-100\%) after second GKS and a median hypesthesia rate of 33\% (range $11 \%-80 \%) .1,5,14,17,22,24-27,29,32,40,42,43,53,54,61-63,67$

Patient Profiles. Patients may have different response profiles to a first stereotactic radiosurgery, and they are heterogeneously represented in the literature: recurrent pain after complete response, ${ }^{14,22,40,61}$ reasonable pain control but significant medication-related side effects or partial response, ${ }^{17,43,54}$ or no response at all. ${ }^{5,24}$ Recurrent pain after complete response is a widely accepted indication for repeat radiosurgery; interventions for the others depend on the center's policy. At Timone University Hospital, the patient criterion for retreatment was initial pain cessation without medication, lasting for at least 1 year.

In the published studies, the median time between first and second radiosurgery was 17 months (range 3-146 months); in the Marseille study it was 72 months (range 12-125 months; Table 3).

Technical Nuances. Technical nuances play a major role in surgical outcomes, especially regarding 2 aspects: target placement and cumulative dose. Secondary issues not specifically related to retreatment are placing 1 versus 2 isocenters, plugging (which increases the length of the treated nerve, the so-called Flickinger effect), and how the nerve recovers after a first GKS.

Target Placement. With some exceptions, ${ }^{40,63}$ most of the studies reported using the DREZ as a retreatment target, with more than $50 \%$ using the identical location the first and second time (Table 4). Some reports, such as that by Zhang et al. ${ }^{67}$ suggested that a longer mean distance between isocenters (2.86 vs $1.93 \mathrm{~mm})$ was associated with better outcomes.

Cumulative Dose. In the studies cumulative dose was reported to range between 40 and 90 Gy at retreatment (Table 4). Cumulative dose as both a value and a cutoff for safety and efficacy remains to be defined. Its real value is not just adding the first and the second dose. Zhang et al. ${ }^{67}$ stated that if the dose at first GKS is 75 Gy and the dose at the second GKS is $40 \mathrm{~Gy}$, with zero as the distance between isocenters, the cumulative dose would be 102 and not 115 Gy (however, biological equivalent dose has not been taken into account in this evaluation). For the same doses, but with a distance of $3 \mathrm{~mm}$ between the shots, Hasegawa et al. ${ }^{22}$ found that the cumulative dose drops to $95 \mathrm{~Gy}$.

Regarding efficacy, Pollock et al. ${ }^{42}$ discussed the issue of a cumulative dose of 163.1 Gy versus lower doses 
TABLE 4: Systematic review of the literature: details of GKS among patients undergoing second GKS*

\begin{tabular}{|c|c|c|c|c|c|}
\hline Authors \& Year & Initial Dose in Gy (range) & 2nd Dose in Gy (range) & $\begin{array}{c}\text { Cumulative Dose in Gy } \\
\text { (range) } \dagger\end{array}$ & Initial Target & 2nd Target \\
\hline present study & median 85 (70-90) & median 90 (70-90) & range $140-180$ & retrogasserian & identical \\
\hline Aubuchon et al., 2011 & mean $87.3(80-90)$ & mean $84.4(60-90)$ & mean $171.7(140-180)$ & $\begin{array}{l}50 \% \text { BS } / \text { plex } \\
\text { triangularis }\end{array}$ & $\begin{array}{l}\text { distally, unless 1st } \\
\text { target distally }\end{array}$ \\
\hline Jones et al., 2011 & 84 & 54 & 178 & $50 \%$ BS & identical \\
\hline Verheul et al., 2010 & 80 & 80 & 160 & REZ & $50 \%$ overlap \\
\hline Dvorak et al., 2009 & median 80 (80-85) & median $45(40-50)$ & median 125 (120-130) & $20 \%$ BS & 2-mm difference \\
\hline Gellner et al., 2008 & mean 75.2 (65-85) & mean $74.3(65-75)$ & $149.5(130-160)$ & REZ (20\% BS) & REZ (20\% BS) \\
\hline Huang et al., 2008 & mean $79(60-90)$ & mean $52(40-76)$ & mean $131(100-166)$ & REZ (20-30\%) & identical \\
\hline Wang et al., 2008 & mean $73.4(60-80)$ & range $60-75$ & range 120-155 & 3-4 mm REZ & identical \\
\hline Sheehan et al., 2005 & median 80 & $\leq 70$ & 150 & NA & NA \\
\hline Urgosik et al., 2005 & range $70-80$ & range $70-80$ & $\begin{array}{l}\text { range } 140-160 \text { (mainly } \\
\text { same dose) }\end{array}$ & $20 \% \mathrm{BS}$ & 2-4 mm distal \\
\hline Zhang et al., 2005 & 75 & 40 & 115 & $40 \% \mathrm{BS}$ & identical \\
\hline Herman et al., 2004 & median $75(70-80)$ & median $70(65-75)$ & median $145(140-155)$ & REZ (20\%) & identical \\
\hline Brisman, 2003 & median 75 & median 40 & 115 & BS $40-50 \%$ & NA \\
\hline Hasegawa et al., 2002 & mean $75.6(50-80)$ & mean $64.4(50-80)$ & $139.4(125-155)$ & $\begin{array}{l}20 \% \text { touched } \\
\text { the BS }\end{array}$ & $\begin{array}{l}\text { anterior to } 1 \text { st w/ only } \\
50 \% \text { overlap }\end{array}$ \\
\hline Shetter et al., 2002 & mean $78.2(35-80)$ & mean $46.6(35-80)$ & $124.8(70-160)$ & BS $50 \%$ & identical \\
\hline Zheng et al., 2001 & mean $75.6(70-90)$ & mean $74.2(70-80)$ & $149.8(140-170)$ & REZ & identical \\
\hline
\end{tabular}

* BS = brainstem; REZ = root entry zone.

$\dagger$ As additive value.

(148.5 Gy in the Pittsburgh group, ${ }^{22} 143.4$ Gy in the Baltimore group, ${ }^{24}$ and 135.7 Gy in the Phoenix group ${ }^{54}$ ) and stated that there was higher initial pain cessation at higher doses, as much as $75 \%$ compared with a range between $19 \%$ and $53 \%$ for the lower doses.

Dvorak et al..$^{14}$ proposed the concept of tailoring the dose to an individual patient. For debilitating pain they propose cumulative doses of more than $130 \mathrm{~Gy}$ and potentially more than 150 Gy and accepting a higher rate of side effects; for patients with reasonable pain control but medication side effects, doses less than 130 Gy seemed more appropriate, with a lower rate of side effects. Dvorak et al. mainly analyzed 7 peer-reviewed papers, accounting for 215 patients, and found an association between cumulative dose and pain control $(p=0.04)$ but also new dysfunction $(p=0.08)$; furthermore, the association between pain control and new dysfunction was strong $(\mathrm{p}=$ 0.02 ). They concluded that a dose of $130 \mathrm{~Gy}$ or more was more successful in terms of pain control but increased dysfunction.

Little et al..$^{38}$ stated that it "seems not to be necessary to decrease the doses in patients with prior trigeminal dysfunction" and also that there is more Level III evidence for ranges of doses between 40 and $70 \mathrm{~Gy}$. Hasega- wa et al. ${ }^{22}$ compared combined high doses (140-160 Gy) versus lower doses (120-135 Gy) and concluded that there was no difference in recurrence rates but that there was increased hypesthesia with the higher doses $(32 \%$ vs $4 \%$ ). They advocated limiting the cumulative dose to 140 Gy. Herman et al. ${ }^{24}$ discussed a cumulative dose of 145 Gy (75 Gy at first GKS and 70 Gy at second GKS), with decreased efficacy but also a low incidence of facial numbness. Hasegawa et al. ${ }^{22}$ suggested that "the best dose would eliminate facial pain completely and preserve facial sensation." To date, there is no established cut-off for dose, and there was a tendency to decrease the dose at second GKS in most studies to avoid dysfunction.

Outcomes. Outcomes are summarized in Table 5 and are detailed below.

Initial Pain Cessation. With repeat radiosurgery, for greater than $50 \%$ relief of initial pain the median was $88 \%$ (range 60\%-100\%); for complete relief, the median was $58 \%$ (range $18.5 \%-90 \%$ ). After initial radiosurgery the ranges were $78 \%-94 \%$ and $32 \%-81 \%$, respectively. After both first and second GKS, most patients became pain free during the first 6 months; the pain cessation rates were fairly consistent with observations after the first GKS. 
Repeat radiosurgery for trigeminal neuralgia

TABLE 5: Systematic review of the literature: results of second GKS

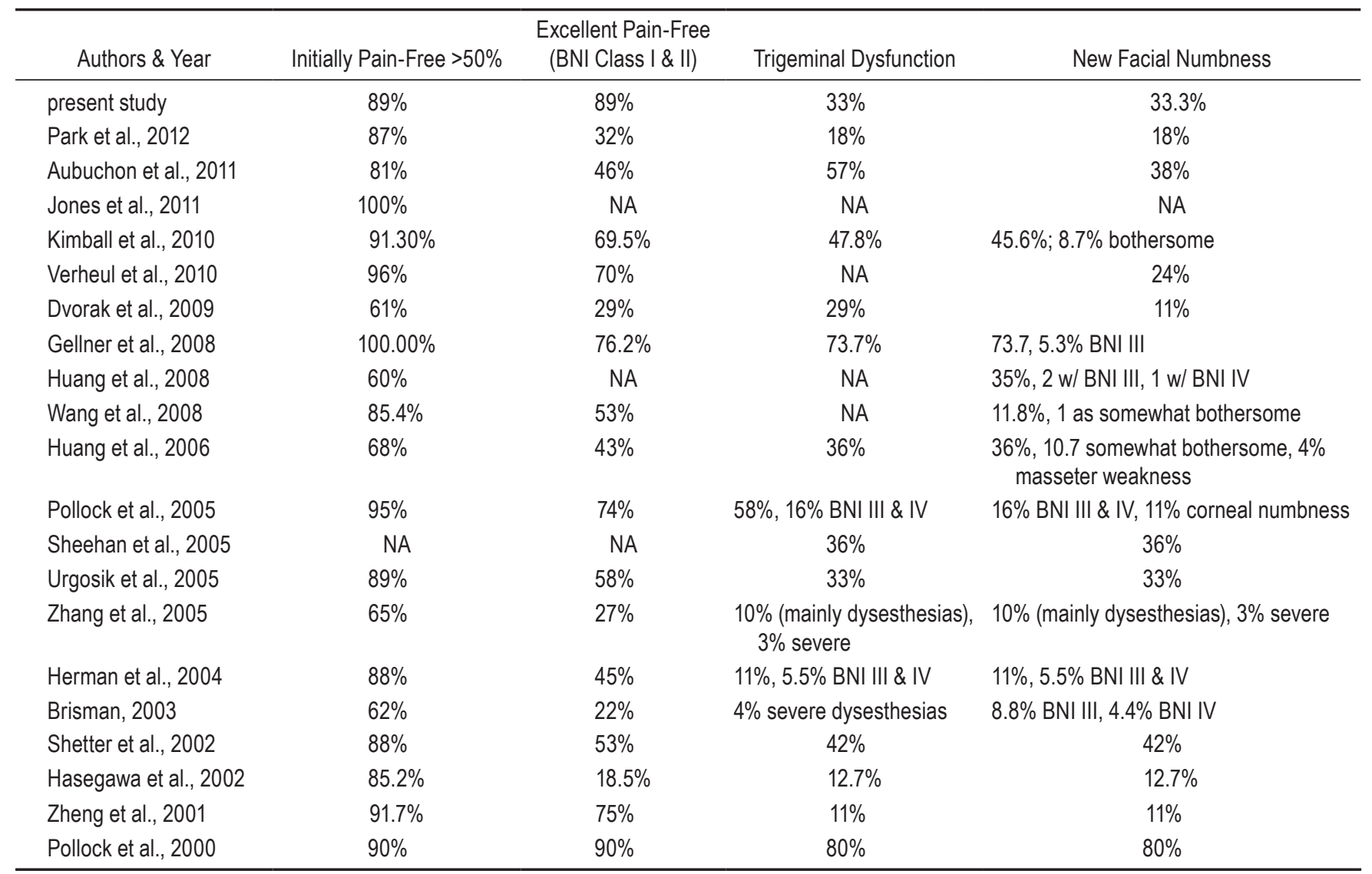

Positive predictive factors for pain cessation rates taken from the published studies are complete pain relief after initial GKS, longer periods of pain relief, reduced topographic distribution of pain after a prior GKS, new trigeminal deficits, increasing isocenter distance between second and first GKS,${ }^{67}$ and higher radiation dose. ${ }^{26} \mathrm{Neg}$ ative predictors are no pain relief after a prior $\mathrm{GKS}^{24}$ and having undergone prior surgical procedure(s). No correlation was found for age, sex, side, additive doses, or interval between first and second GKS $5,27,32$ (Table 6).

Hypesthesia. The median rate for new hypesthesia after repeat GKS was 33\% (range 11\%-80\%), much higher than that reported for first GKS (6\%-54\%). The main problem might not even be hypesthesia per se with retreatment but such complications as bothersome hypesthesia (up to $16 \%$ ), ${ }^{17,42}$ corneal numbness (up to $11 \%$ ), ${ }^{1,42}$ dry eye (up to $10.9 \%$ ), ${ }^{32}$ taste changes (up to $8.7 \%$ ), ${ }^{32}$ jaw weakness (up to $4 \%$ ), ${ }^{32}$ and anesthesia dolorosa (which was difficult to quantify due to heterogeneity and lack of reporting). ${ }^{1}$

Positive predictive factors for new hypesthesia after second GKS, taken from the published studies, are good response to initial GKS (even at low doses), an additive dose greater than $115 \mathrm{~Gy}$, isocenter placement (nearly identical location being reported by some studies as creating dysfunction), cumulative radiation dose to the lateral pons (cutoff of $44 \mathrm{~Gy}$ ), and cumulative DREZ dose (cutoff of $84.3 \mathrm{~Gy}$ ). ${ }^{1}$ No correlation was found with regard to prior surgeries, ${ }^{26}$ pretreatment sensory impairment, first and/or second dose or additive doses, ${ }^{26}$ or the distance between isocenters (considered by other studies to be a positive predictor) ${ }^{42}$ (Table 7).

Summarizing current literature, hypesthesia onset is suggested to be a predictor for better long-term outcome but is not mandatory for maintaining pain relief. Also, in some studies, the occurrence of hypesthesia reached rates comparable to those with radiofrequency lesioning and/or balloon microcompression. Retreatment is more injuring than a first GKS.

Maintaining Pain Relief. As with all other techniques for TN, a second GKS is not a definitive therapy. There are 2 important issues when discussing maintenance of pain relief after second GKS: one is the necessity of having long-term follow-up, as recurrences are more likely to occur 15-18 months after treatment; the second is that reported rates are fairly consistent or better compared with results of the first GKS (but there is shorter available follow-up compared with first treatment).

In the published studies, recurrences ranged between $5.3 \%$ and $32 \%$ in the short term (median 24 months). Among studies reporting long-term follow-up, rates for maintaining pain relief at 5 years varied between $44.2 \%{ }^{40}$ and $72.7 \% .{ }^{17}$ Additionally, in some studies, such as that by Verheul et al. ${ }^{62}$ the curves for first and second GKS are almost identical for this outcome. 
TABLE 6: Systematic review of the literature: predictors of initial pain cessation after second GKS

positive predictors
initial complete pain relief after a prior GKS
longer periods of pain relief after 1st GKS
reduced distribution after 1st GKS
new trigeminal deficits
increasing distance btwn isocenters of 1 st \& 2nd radiation dose
negative predictors
no pain relief after a prior GKS
prior surgical procedure
no correlation
age
sex
side
interval btwn GKS procedures
dose rate at 2nd GKS
radiation dose

Positive predictive factors were partial recurrence after first GKS (partial better than complete), recurrence in a reduced topographic distribution, and additional sensory dysfunction after a first treatment. ${ }^{32}$

\section{Discussion}

Medically unresponsive TN can be treated by 3 methods: MVD, percutaneous techniques, and GKS. With the MVD technique, Barker et al. ${ }^{2}$ reported up to $70 \%$ of patients remaining pain free at 10 years; for patients undergoing repeat MVD, $42 \%$ of cases had excellent results at 10 years. Depending on the study, MVD recurrence rates on long-term basis range between $15 \%$ and 35\%. ${ }^{2-4,7,8,10-12,18,28,30,52,55,56}$ For percutaneous techniques, such as thermocoagulation, some trials reported a $57.7 \%$ pain-free response after a first procedure and up

TABLE 7: Systematic review of the literature: predictors of hypesthesia onset

positive predictors
prior surgeries
good response to initial GKS (even if 2nd GKS performed at low
doses)
reduced distribution after 1st GKS
an additive dose above 115 Gy
nearly identical isocenter locations \& mean dysfunction
cumulative max radiation dose to lateral pons (cutoff 44 Gy)
no correlation
prior surgeries
pretreatment sensory impairment
1st \&/or 2nd dose, additive dose
distance btwn isocenters
which isocenter closer to brainstem

to $94 \%$ at 5-year follow-up after a second procedure. ${ }^{31} \mathrm{Fa}-$ cial numbness has been reported to occur in between $58 \%$ and $79 \%$ of patients. ${ }^{9,65}$ Gybels and Sweet ${ }^{19}$ reviewed 8 published studies on thermocoagulation, involving more than 600 procedures; corneal numbness ranged from $1 \%$ to $35 \%$ and anesthesia dolorosa, from $0.6 \%$ to $25 \%$.

Repeat radiosurgery emerged as an alternative to these 2 techniques, especially during the last 10 years. A number of clinical retrospective trials have shown that second GKS is a safe and effective procedure, with comparable or better initial pain cessation rates, despite a higher toxicity, which seems to be the tradeoff for maintaining pain relief. $1,5,14,17,22,24-27,32,38,42,63$ Nevertheless, there is little consistent information to council patients on an individual basis, due to heterogeneity among papers regarding selection criteria and treatment parameters.

Among the 497 patients included in our study with initial pain cessation after the first GKS, 34.4\% (157 of 456 with $\geq 1$-year follow-up) experienced at least 1 recurrence; 112 of 157 required further treatment. Thirteen (1.8\%) of the 737 patients were considered for a second GKS, a rate smaller than found in the published peerreviewed papers, which ranged in from $7 \%$ to $23.7 \% \%^{26}$ (Table 3); this is explained by a different strategy of repeat GKS in our study.

Patient selection for retreatment is probably one of the most important issues. Why to retreat, when to retreat, and the patient profile are key conditions for therapeutic success. Our center uses strict selection criteria for second GKS, related to an initial and prolonged pain cessation without medication, in the absence of other surgical alternatives. This is suggested by the median time for retreatment in our study, 72 months (range 12-125 months), compared with 17 months (range 12-125 months) in the literature reviewed. Also, previous studies discussing first GKS showed improved outcomes with no atypical features,,$^{39,44}$ no prior surgical treatment, ${ }^{6,39,41}$ or no new trigeminal deficits. ${ }^{6,44}$ When reporting outcomes, we believe that these types of cases should be clearly separated.

Additionally, individual patient sensitivity to irradiation might play a role. We might be selecting a subgroup of patients sensitive to radiation when treating only those responding well to the first GKS.

Another issue is related to doses. For GKS, a minimum dose of 70 Gy necessary for efficacy was established in 1996 by a multicenter trial. ${ }^{34}$ As a maximum, in a baboon model Kondziolka et al..$^{33}$ suggested that necrosis occurred at $100 \mathrm{~Gy}$. In this range, higher doses are related to better efficacy. ${ }^{53,64}$ Thus, our policy is to deliver $90 \mathrm{~Gy}$ at $100 \%$ isodose, whenever the morphology of the cistern allows this dose prescription, while keeping doses to the brainstem low. This dose allows a low rate of toxicity, provided that we use the retrogasserian target (7-8 $\mathrm{mm}$ from the emergence). ${ }^{48}$ We kept the same dose and the same target placement at first and second GKS.

The radiation target is important with respect to initial pain cessation and side effects. The heterogeneity regarding radiation target in published studies makes the "ideal" target difficult to establish.

Current literature is sparse, and there is a need for more follow-up and uniformity to establish state-of-the- 
art safety and efficacy for GKS retreatment. Pain control and recurrence rates seem comparable with first GKS in the literature we reviewed, with higher hypesthesia rates at second GKS in almost all studies. When investigating safety and efficacy, particular attention should be paid to individual patient characteristics at baseline, as well as to technical nuances, mainly target placement and radiation dose; additionally, the number of patients and duration of follow-up are important criteria.

Besides the relatively small sample size, our study raises the question of surgical alternatives after failed GKS for TN. The rates of initial pain cessation and recurrence seem comparable to or even better than those for the first GKS, according to different studies, but the toxicity is much higher, both in our study and in the published data. However, because of the small number of patients in our study and limited available follow-up and heterogeneity of treatment philosophies in the reviewed studies, we do not have the answer to the 3 cardinal questions regarding repeat radiosurgery in recurrent TN: which patients to retreat, which target is optimal, and which dose is optimal. Reassessment of our database in 20 years' time may offer sufficient numbers to answer these questions.

\section{Conclusions}

Our study is small compared with our general cohort due to very strict selection criteria for retreatment, mainly related to an initial and prolonged pain cessation without medication, in the absence of other surgical alternatives. Our study is differentiated from the other published studies by the use of the same technical parameters as the first GKS and much longer delay between first and second GKS, with a median of 72 months (range 12-125 months) at our institution compared with 17 months (range 3-146 months) in the literature. Current available studies suggest that second GKS is safe and effective, with an important increase in hypesthesia rates. Our attitude, due to this higher toxicity, is to propose MVD as a first intention therapy for recurrent TN after first GKS and to reserve second GKS for cases with no other surgical alternative.

\section{Disclosure}

This study received funding from Timone University Hospital, Assistance-Publique, Hôpitaux de Marseille, France. Dr. Régis received congress organization sponsoring from Accuray, Brainlab, Elekta, and Varian. The other authors report no conflict of interest concerning the materials or methods used in this study or the findings specified in this paper.

Author contributions to the study and manuscript preparation include the following. Conception and design: Tuleasca, Levivier, Régis. Acquisition of data: Tuleasca, Donnet, Roussel, Régis. Analysis and interpretation of data: Tuleasca, Carron, Donnet, Roussel, Levivier, Régis. Drafting the article: Tuleasca. Critically revising the article: Tuleasca, Carron, Donnet, Levivier, Régis. Reviewed submitted version of manuscript: all authors. Approved the final version of the manuscript on behalf of all authors: Tuleasca. Statistical analysis: Resseguier, Gaudart. Administrative/technical/material support: Levivier, Régis. Study supervision: Levivier, Régis.

\section{References}

1. Aubuchon AC, Chan MD, Lovato JF, Balamucki CJ, Ellis TL,
Tatter SB, et al: Repeat Gamma Knife radiosurgery for trigeminal neuralgia. Int J Radiat Oncol Biol Phys 81:10591065, 2011

2. Barker FG II, Jannetta PJ, Bissonette DJ, Larkins MV, Jho HD: The long-term outcome of microvascular decompression for trigeminal neuralgia. N Engl J Med 334:1077-1083, 1996

3. Bederson JB, Wilson CB: Evaluation of microvascular decompression and partial sensory rhizotomy in 252 cases of trigeminal neuralgia. J Neurosurg 71:359-367, 1989

4. Brisman R: Microvascular decompression vs. Gamma Knife radiosurgery for typical trigeminal neuralgia: preliminary findings. Stereotact Funct Neurosurg 85:94-98, 2007

5. Brisman R: Repeat Gamma Knife radiosurgery for trigeminal neuralgia. Stereotact Funct Neurosurg 81:43-49, 2003

6. Brisman R, Khandji AG, Mooij RB: Trigeminal nerve-blood vessel relationship as revealed by high-resolution magnetic resonance imaging and its effect on pain relief after Gamma Knife radiosurgery for trigeminal neuralgia. Neurosurgery 50:1261-1267, 2002

7. Broggi G, Ferroli P, Franzini A, Pluderi M, La Mantia L, Milanese C: Role of microvascular decompression in trigeminal neuralgia and multiple sclerosis. Lancet 354:1878-1879, 1999

8. Broggi G, Ferroli P, Franzini A, Servello D, Dones I: Microvascular decompression for trigeminal neuralgia: comments on a series of 250 cases, including 10 patients with multiple sclerosis. J Neurol Neurosurg Psychiatry 68:59-64, 2000

9. Brown JA, McDaniel MD, Weaver MT: Percutaneous trigeminal nerve compression for treatment of trigeminal neuralgia: results in 50 patients. Neurosurgery 32:570-573, 1993

10. Burchiel KJ: Editorial. Microvascular decompression for trigeminal neuralgia. J Neurosurg 108:687-688, 2008

11. Burchiel KJ, Clarke H, Haglund M, Loeser JD: Long-term efficacy of microvascular decompression in trigeminal neuralgia. J Neurosurg 69:35-38, 1988

12. Chen JC: Microvascular decompression for trigeminal neuralgia in patients with and without prior stereotactic radiosurgery. World Neurosurg 78:149-154, 2012

13. Chen JC, Girvigian M, Greathouse H, Miller M, Rahimian $\mathrm{J}$ : Treatment of trigeminal neuralgia with linear accelerator radiosurgery: initial results. J Neurosurg 101 Suppl 3:346350,2004

14. Dvorak T, Finn A, Price LL, Mignano JE, Fitzek MM, Wu JK, et al: Retreatment of trigeminal neuralgia with Gamma Knife radiosurgery: is there an appropriate cumulative dose? Clinical article. J Neurosurg 111:359-364, 2009

15. Eller JL, Raslan AM, Burchiel KJ: Trigeminal neuralgia: definition and classification. Neurosurg Focus 18(5):E3, 2005

16. Flickinger JC, Pollock BE, Kondziolka D, Phuong LK, Foote RL, Stafford SL, et al: Does increased nerve length within the treatment volume improve trigeminal neuralgia radiosurgery? A prospective double-blind, randomized study. Int J Radiat Oncol Biol Phys 51:449-454, 2001

17. Gellner V, Kurschel S, Kreil W, Holl EM, Ofner-Kopeinig P, Unger F: Recurrent trigeminal neuralgia: long term outcome of repeat Gamma Knife radiosurgery. J Neurol Neurosurg Psychiatry 79:1405-1407, 2008

18. Gronseth G, Cruccu G, Alksne J, Argoff C, Brainin M, Burchiel $\mathrm{K}$, et al: Practice parameter: the diagnostic evaluation and treatment of trigeminal neuralgia (an evidence-based review): report of the Quality Standards Subcommittee of the American Academy of Neurology and the European Federation of Neurological Societies. Neurology 71:1183-1190, 2008

19. Gybels JM, Sweet WH: Neurosurgical treatment of persistent pain. Physiological and pathological mechanisms of human pain. Pain Headache 11:1-402, 1989

20. Håkanson S: Transoval trigeminal cisternography. Surg Neurol 10:137-144, 1978

21. Håkanson S: Trigeminal neuralgia treated by the injection of 
glycerol into the trigeminal cistern. Neurosurgery 9:638646, 1981

22. Hasegawa T, Kondziolka D, Spiro R, Flickinger JC, Lunsford LD: Repeat radiosurgery for refractory trigeminal neuralgia. Neurosurgery 50:494-502, 2002

23. Headache Classification Subcommittee of the International Headache Society: The International Classification of Headache Disorders: 2nd edition. Cephalalgia 24 Suppl 1:9-160, 2004

24. Herman JM, Petit JH, Amin P, Kwok Y, Dutta PR, Chin LS: Repeat Gamma Knife radiosurgery for refractory or recurrent trigeminal neuralgia: treatment outcomes and quality-of-life assessment. Int J Radiat Oncol Biol Phys 59:112-116, 2004

25. Huang CF, Chiou SY, Wu MF, Tu HT, Liu WS: Gamma Knife surgery for recurrent or residual trigeminal neuralgia after a failed initial procedure. Clinical article. J Neurosurg 113 Suppl:172-177, 2010

26. Huang CF, Chuang JC, Tu HT, Lin LY: Repeated Gamma Knife surgery for refractory trigeminal neuralgia. J Neurosurg 105 Suppl:99-102, 2006

27. Huang CF, Tu HT, Liu WS, Chiou SY, Lin LY: Gamma Knife surgery used as primary and repeated treatment for idiopathic trigeminal neuralgia. J Neurosurg 109 Suppl:179-184, 2008

28. Jannetta PJ: Microvascular decompression of the trigeminal root entry zone. Theoretical considerations, operative anatomy, surgical technique, and results, in Rovit RL, Murali R, Janneta PJ (eds): Trigeminal Neuralgia. Baltimore: Williams \& Wilkins, 1990, pp 201-222

29. Jones GC, Elaimy AL, Demakas JJ, Jiang H, Lamoreaux WT, Fairbanks RK, et al: Feasibility of multiple repeat Gamma Knife radiosurgeries for trigeminal neuralgia: a case report and review of the literature. Case Rep Med 2011:258910, 2011

30. Kalkanis SN, Eskandar EN, Carter BS, Barker FG II: Microvascular decompression surgery in the United States, 1996 to 2000: mortality rates, morbidity rates, and the effects of hospital and surgeon volumes. Neurosurgery 52:1251-1262, 2003

31. Kanpolat Y, Savas A, Bekar A, Berk C: Percutaneous controlled radiofrequency trigeminal rhizotomy for the treatment of idiopathic trigeminal neuralgia: 25-year experience with 1,600 patients. Neurosurgery 48:524-534, 2001

32. Kimball BY, Sorenson JM, Cunningham D: Repeat Gamma Knife surgery for trigeminal neuralgia: long-term results. Clinical article. J Neurosurg 113 Suppl:178-183, 2010

33. Kondziolka D, Lacomis D, Niranjan A, Mori Y, Maesawa S, Fellows W, et al: Histological effects of trigeminal nerve radiosurgery in a primate model: implications for trigeminal neuralgia radiosurgery. Neurosurgery 46:971-977, 2000

34. Kondziolka D, Lunsford LD, Flickinger JC, Young RF, Vermeulen S, Duma CM, et al: Stereotactic radiosurgery for trigeminal neuralgia: a multiinstitutional study using the gamma unit. J Neurosurg 84:940-945, 1996

35. Leksell L: The stereotaxic method and radiosurgery of the brain. Acta Chir Scand 102:316-319, 1951

36. Leksell L: Sterotaxic radiosurgery in trigeminal neuralgia. Acta Chir Scand 137:311-314, 1971

37. Lindquist C: Gamma Knife surgery: evolution and long-term results, in Kondziolka D (ed): Radiosurgery. Basel, Switzerland: Karger, 2000, Vol 3, pp 1-12

38. Little AS, Shetter AG, Shetter ME, Kakarla UK, Rogers CL: Salvage Gamma Knife stereotactic radiosurgery for surgically refractory trigeminal neuralgia. Int J Radiat Oncol Biol Phys 74:522-527, 2009

39. Maesawa S, Salame C, Flickinger JC, Pirris S, Kondziolka D, Lunsford LD: Clinical outcomes after stereotactic radiosurgery for idiopathic trigeminal neuralgia. J Neurosurg 94:14-20, 2001

40. Park KJ, Kondziolka D, Berkowitz O, Kano H, Novotny J Jr, Niranjan A, et al: Repeat Gamma Knife radiosurgery for trigeminal neuralgia. Neurosurgery 70:295-305, 2012
41. Petit JH, Herman JM, Nagda S, DiBiase SJ, Chin LS: Radiosurgical treatment of trigeminal neuralgia: evaluating quality of life and treatment outcomes. Int J Radiat Oncol Biol Phys 56:1147-1153, 2003

42. Pollock BE, Foote RL, Link MJ, Stafford SL, Brown PD, Schomberg PJ: Repeat radiosurgery for idiopathic trigeminal neuralgia. Int J Radiat Oncol Biol Phys 61:192-195, 2005

43. Pollock BE, Foote RL, Stafford SL, Link MJ, Gorman DA, Schomberg PJ: Results of repeated Gamma Knife radiosurgery for medically unresponsive trigeminal neuralgia. J Neurosurg 93 Suppl 3:162-164, 2000

44. Pollock BE, Phuong LK, Gorman DA, Foote RL, Stafford SL: Stereotactic radiosurgery for idiopathic trigeminal neuralgia. J Neurosurg 97:347-353, 2002

45. Rand RW: Leksell Gamma Knife treatment of tic douloureux. Neurosurg Clin N Am 8:75-78, 1997

46. Rand RW, Jacques DB, Melbye RW, Copcutt BG, Levenick MN, Fisher MR: Leksell Gamma Knife treatment of tic douloureux. Stereotact Funct Neurosurg 61 Suppl 1:93-102, 1993

47. Régis J, Arkha Y, Yomo S, Murata N, Roussel P, Donnet A, et al: [Radiosurgery in trigeminal neuralgia: long-term results and influence of operative nuances.] Neurochirurgie 55:213222, 2009 (Fr)

48. Régis J, Carron R, Tuleasca C, Donnet A: Distal radiosurgical targeting for trigeminal neuralgia, in Sheehan JP, Gerszten PC (eds): Controversies in Stereotactic Radiosurgery: Best Evidence Recommendations. New York: Thieme, 2014, pp 120-130

49. Régis J, Metellus P, Hayashi M, Roussel P, Donnet A, BilleTurc F: Prospective controlled trial of Gamma Knife surgery for essential trigeminal neuralgia. J Neurosurg 104:913-924, 2006

50. Régis J, Tuleasca C: Editorial. Fifteen years of Gamma Knife surgery for trigeminal neuralgia in the Journal of Neurosurgery: history of a revolution in functional neurosurgery. $\mathbf{J}$ Neurosurg 115 Suppl:2-7, 2011

51. Rogers CL, Shetter AG, Fiedler JA, Smith KA, Han PP, Speiser BL: Gamma Knife radiosurgery for trigeminal neuralgia: the initial experience of the Barrow Neurological Institute. Int $\mathbf{J}$ Radiat Oncol Biol Phys 47:1013-1019, 2000

52. Sekula RF, Marchan EM, Fletcher LH, Casey KF, Jannetta PJ: Microvascular decompression for trigeminal neuralgia in elderly patients. J Neurosurg 108:689-691, 2008

53. Sheehan J, Pan HC, Stroila M, Steiner L: Gamma Knife surgery for trigeminal neuralgia: outcomes and prognostic factors. J Neurosurg 102:434-441, 2005

54. Shetter AG, Rogers CL, Ponce F, Fiedler JA, Smith K, Speiser BL: Gamma Knife radiosurgery for recurrent trigeminal neuralgia. J Neurosurg 97 (5 Suppl):536-538, 2002

55. Sindou M (ed): Microvascular decompression for trigeminal neuralgia, in: Practical Handbook of Neurosurgery: From Leading Neurosurgeons. Volume 3: Spine, Functional, Peripheral Nerves. Vienna: Springer, 2009, pp 333-348

56. Sindou M, Leston J, Decullier E, Chapuis F: Microvascular decompression for primary trigeminal neuralgia: long-term effectiveness and prognostic factors in a series of 362 consecutive patients with clear-cut neurovascular conflicts who underwent pure decompression. J Neurosurg 107:1144-1153, 2007

57. Smith ZA, Gorgulho AA, Bezrukiy N, McArthur D, Agazaryan N, Selch MT, et al: Dedicated linear accelerator radiosurgery for trigeminal neuralgia: a single-center experience in 179 patients with varied dose prescriptions and treatment plans. Int J Radiat Oncol Biol Phys 81:225-231, 2011

58. Tuleasca C, Carron R, Resseguier N, Donnet A, Roussel P, Gaudart J, et al: Multiple sclerosis-related trigeminal neuralgia: a prospective series of 43 patients treated with Gamma Knife surgery with more than one year of follow-up. Stereotact Funct Neurosurg 92:203-210, 2014

59. Tuleasca C, Carron R, Resseguier N, Donnet A, Roussel P, 


\section{Repeat radiosurgery for trigeminal neuralgia}

Gaudart J, et al: Patterns of pain-free response in 497 cases of classic trigeminal neuralgia treated with Gamma Knife surgery and followed up for least 1 year. Clinical article. J Neurosurg 117 Suppl:181-188, 2012

60. Tuleasca C, Carron R, Resseguier N, Donnet A, Roussel P, Gaudart J, et al: Trigeminal neuralgia related to megadolichobasilar artery compression: a prospective series of twenty-nine patients treated with Gamma Knife surgery, with more than one year of follow-up. Stereotact Funct Neurosurg 92:170-177, 2014

61. Urgosik D, Liscak R, Novotny J Jr, Vymazal J, Vladyka V: Treatment of essential trigeminal neuralgia with Gamma Knife surgery. J Neurosurg 102 Suppl:29-33, 2005

62. Verheul JB, Hanssens PE, Lie ST, Leenstra S, Piersma H, Beute GN: Gamma Knife surgery for trigeminal neuralgia: a review of 450 consecutive cases. Clinical article. J Neurosurg 113 Suppl:160-167, 2010

63. Wang L, Zhao ZW, Qin HZ, Li WT, Zhang H, Zong JH, et al: Repeat Gamma Knife radiosurgery for recurrent or refractory trigeminal neuralgia. Neurol India 56:36-41, 2008

64. Young B, Shivazad A, Kryscio RJ, St. Clair W, Bush HM: Long-term outcome of high-dose Gamma Knife surgery in treatment of trigeminal neuralgia. Clinical article. J Neurosurg 119:1166-1175, 2013
65. Young RF: Glycerol rhizolysis for treatment of trigeminal neuralgia. J Neurosurg 69:39-45, 1988

66. Zakrzewska JM, Thomas DG: Patient's assessment of outcome after three surgical procedures for the management of trigeminal neuralgia. Acta Neurochir (Wien) 122:225-230, 1993

67. Zhang P, Brisman R, Choi J, Li X: Where to locate the isocenter? The treatment strategy for repeat trigeminal neuralgia radiosurgery. Int J Radiat Oncol Biol Phys 62:38-43, 2005

68. Zheng LG, Xu DS, Kang CS, Zhang ZY, Li YH, Zhang YP, et al: Stereotactic radiosurgery for primary trigeminal neuralgia using the Leksell Gamma unit. Stereotact Funct Neurosurg 76:29-35, 2001

Manuscript submitted June 29, 2014.

Accepted August 1, 2014.

Please include this information when citing this paper: DOI: 10.3171/2014.8.GKS141487.

Address correspondence to: Constantin Tuleasca, M.D., Lausanne University Hospital, Neurosurgery Service and Gamma Knife Center, Rue de Bugnon 44-46, BH-08, CH-1011 Lausanne, Switzerland.email: constantin.tuleasca@gmail.com. 